\title{
Computational Modeling of Uranium Hydriding and Complexes
}

\author{
K. Balasubramanian, W.J. Siekhaus, W. McLean II
}

This article was submitted to Plutonium Futures - The Science Conference, Albuquerque, NM, July 6-10, 2003

\section{February 3, 2003}

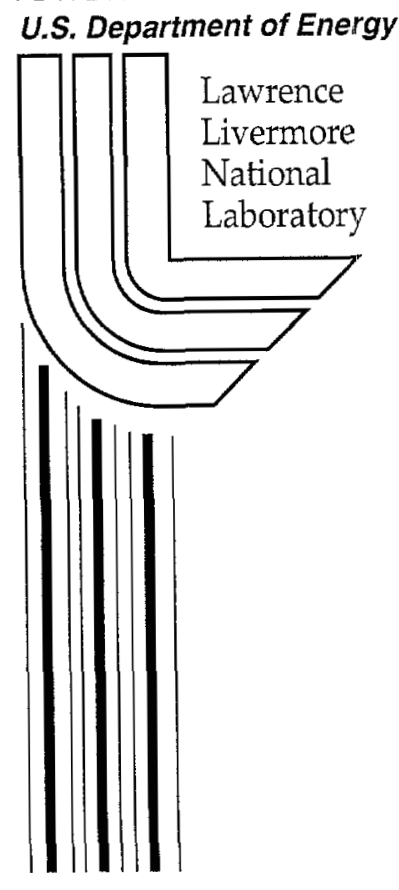




\section{DISCLAIMER}

This document was prepared as an account of work sponsored by an agency of the United States Government. Neither the United States Government nor the University of California nor any of their employees, makes any warranty, express or implied, or assumes any legal liability or responsibility for the accuracy, completeness, or usefulness of any information, apparatus, product, or process disclosed, or represents that its use would not infringe privately owned rights. Reference herein to any specific commercial product, process, or service by trade name, trademark, manufacturer, or otherwise, does not necessarily constitute or imply its endorsement, recommendation, or favoring by the United States Government or the University of California. The views and opinions of authors expressed herein do not necessarily state or reflect those of the United States Government or the University of California, and shall not be used for advertising or product endorsement purposes.

This is a preprint of a paper intended for publication in a journal or proceedings. Since changes may be made before publication, this preprint is made available with the understanding that it will not be cited or reproduced without the permission of the author.

This report has been reproduced directly from the best available copy.

Available electronically at http://www.doc.gov/bridge

Available for a processing fee to U.S. Department of Energy

And its contractors in paper from

U.S. Department of Energy

Office of Scientific and Technical Information

P.O. Box 62

Oak Ridge, TN 37831-0062

Telephone: (865) 576-8401

Facsimile: (865) 576-5728

E-mail: reports@adonis.osti.gov

Available for the sale to the public from

U.S. Department of Commerce

National Technical Information Service

5285 Port Royal Road

Springfield, VA 22161

Telephone: (800) 553-6847

Facsimile: (703) 605-6900

E-mail: orders@ntis.fedworld.gov

Online ordering: http://www.ntis.gov/ordering.htm

OR

Lawrence Livermore National Laboratory

Technical Information Department's Digital Library

http://www.llnl.gov/tid/Library.html 


\section{Computational Modeling of Uranium Hydriding and complexes}

K. Balasubramanian, Wigbert J. Siekhaus and William McLean II

Chemistry and Material Science Directorate, Lawrence Livermore National

Laboratory, University of California, Livermore CA 94550 


\section{Introduction}

Uranium hydriding is one of the most important processes that has received considerable attention over many years ${ }^{1-7}$. Although many experimental and modeling studies have been carried out concerning thermochemistry, diffusion kinetics and mechanisms of U-hydriding, very little is known about the electronic structure and electronic features that govern the U-hydriding process. Yet it is the electronic feature that controls the activation barrier and thus the rate of hydriding. Moreover the role of impurities and the role of the product $\mathrm{UH}_{3}$ on hydriding rating are not fully understood.

An early study by Condon and Larson ${ }^{1}$ concerns with the kinetics of U-hydrogen system and a mathematical model for the U-hydriding process. They proposed that diffusion in the reactant phase by hydrogen before nucleation to form hydride phase and that the reaction is first order for hydriding and zero order for dehydriding. Condon ${ }^{2}$ has also calculated and measures the reaction rates of U-hydriding and proposed a diffusion model for the U-hydriding. This model was found to be in excellent agreement with the experimental reaction rates. From the slopes of the Arrhenius plot the activation energy was calculated as $6.35 \mathrm{kcal} / \mathrm{mole}$. In a subsequent study Kirkpatrick ${ }^{3}$ formulated a closeform for approximate solution to Condon's equation. Bloch and Mintz $z^{4}$ have proposed the kinetics and mechanism for the U-H reaction over a wide range of pressures and temperatures. They have discussed their results through two models, one, which considers hydrogen diffusion through a protective $\mathrm{UH}_{3}$ product layer, and the second where hydride growth occurs at the hydride-metal interface. These authors obtained twodimensional fits of experimental data to the pressure-temperature reactions. Kirkpatrick and Condon $^{5}$ have obtained a linear solution to hydriding of uranium. These authors showed that the calculated reaction rates compared quite well with the experimental data at a hydrogen pressure of $1 \mathrm{~atm}$.

Powell et al. ${ }^{6}$ have studied U-hydriding in ultrahigh vacuum and obtained the linear rate data over a wide range of temperatures and pressures. They found reversible hydrogen sorption on the $\mathrm{UH}_{3}$ reaction product from kinetic effects at $21^{\circ} \mathrm{C}$. This demonstrates restarting of the hydriding process in the presence of $\mathrm{UH}_{3}$ reaction product. 
DeMint and Leckey ${ }^{7}$ have shown that Si impurities dramatically accelerate the Uhydriding rates.

We report our recent results of relativistic computations ${ }^{8}$ that vary from complete active space multi-configuration interaction (CAS-MCSCF) followed by multi-reference configuration interaction (MRSDCI) computations that included up to 50 million configurations for modeling of uranium-hydriding with cluster models will be presented.

\section{Results}

Figure 1 shows our computed potential energy surface for the insertion of a $U$ site into $\mathrm{H}_{2}$. As seen from Fig.1, pure $\mathrm{U}$ site has to surpass a barrier of $20.9 \mathrm{kcal} / \mathrm{mole}$ for the U-hydriding. Once the barrier is surpassed a stable product is formed which is 22.4 $\mathrm{kcal} / \mathrm{mole}$ more stable than the reactants. Figure 2 shows the potential energy surface of an additional $\mathrm{H}_{2}$ approaching $\mathrm{UH}_{3}$ as modeled by $\mathrm{U}^{+3}$ interaction with $\mathrm{H}_{2}$. The product $\mathrm{UH}_{3}$ is highly ionic and thus $\mathrm{U}$ transfers electron density to the three hydrogens resulting in a $\mathrm{U}^{+3}$ state. As seen from Fig. $2, \mathrm{U}^{+3}$ inserts into $\mathrm{H}_{2}$ spontaneously thus demonstrating the $\mathrm{U}^{3}$-site in the product $\mathrm{UH}_{3}$ binds to $\mathrm{H}_{2}$ spontaneously forming a complex in which $\mathrm{H}_{2}$ is separated far enough so as to cause liberation of $\mathrm{H}$ atoms in the presence of $\mathrm{U}$.

\section{Discussion}

Our computed potential energy surfaces demonstrate a $21 \mathrm{kcal} /$ mole activation energy barrier for pure $\mathrm{U}$ reaction with $\mathrm{H}_{2}$. However, the presence of the product $\mathrm{UH}_{3}$ catalyzes the U-hydriding. We have also modeled the presence of Si impurities for the Uhydriding reaction to show that the activation barrier is lowered by the presence of $\mathrm{Si}$. Our computations reveal an electron donor-acceptor model for the U-hydriding, where $\mathrm{H}_{2}$ exchanges electronic density from its occupied $1 \sigma_{\mathrm{g}}$ orbital to the $\mathrm{U}(6 \mathrm{~d} \sigma)$ orbital and back donation from the $\mathrm{U}(6 \mathrm{~d} \pi)$ orbital back to $\mathrm{H}_{2} 1 \sigma_{\mathrm{u}}$ antibonding orbital causes the dissociation of $\mathrm{H}_{2}$ by $\mathrm{U}$. In particular the $5 \mathrm{f}$ or $7 \mathrm{~s}$ orbitals of $\mathrm{U}$ are not involved in the dissociation of $\mathrm{H}_{2}$. We also show that $\mathrm{Si}$ impurities assist the hydriding process by the spontaneous insertion of the ${ }^{1} \mathrm{D}$ state of Si into $\mathrm{H}_{2}$. The $\mathrm{UH}_{3}$ product catalyzes the hydriding process by spontaneous formation of a complex of $\mathrm{H}_{2}$ at the $\mathrm{U}^{+3}$ site, which opens up the $\mathrm{H}_{2}$ bond sufficiently to cause further U-hydriding to occur spontaneously. The bond breaking process in the formation complex assists the formation of $\mathrm{H}$ atoms in 
the presence of $U$. The hydrogen atoms thus formed diffuse through the cracks to cause further U-hydriding thus explaining the experimental observation of Powell et al.

\section{REFERENCES}

${ }^{1}$ J. B. Condon, and E. A. Larson, J. Chem. Phys., 59, 855 (1973).

${ }^{2}$ J. B. Condon, J. Phys. Chem., 79, 392 (1975).

${ }^{3}$ J. R. Kirkpatrick, J. Phys. Chem. 85, 3444 (1981).

${ }^{4}$ J. Bloch and M. H. Mintz, J. Less Common Metals., 81, 301 (1981).

5 J. R. Kirkpatrick and J. B. Condon, "Modeling Reaction Between Uranium and Hydrogen", Oakridge National Lab, Internal Report, K/CSD/TM-87, 1990 p1-41

${ }^{6}$ G. L. Powell, W. L. Harper, and J. R. Kirkpatrick, J. Less Common Metals., 172, 116 (1991).

${ }^{7}$ A. L. Demint and J. H. Leckey, J. Nuc. Mat. 281, 208 (2000).

${ }^{8}$ K. Balasubramanian, Relativistic Effects in Chemistry: Part A: Theory and Techniques, Wiley Interscience, New York, NY, p 301 1997.; K. Balasubramanian, Relativistic Effects in Chemistry Part B. Applications to Molecules \& Clusters, Wiley Interscience, New York, NY, p527, 1997. 
Ve have calculated a $21 \mathrm{Kcal} /$ mole activation barrier for the U-hydriding

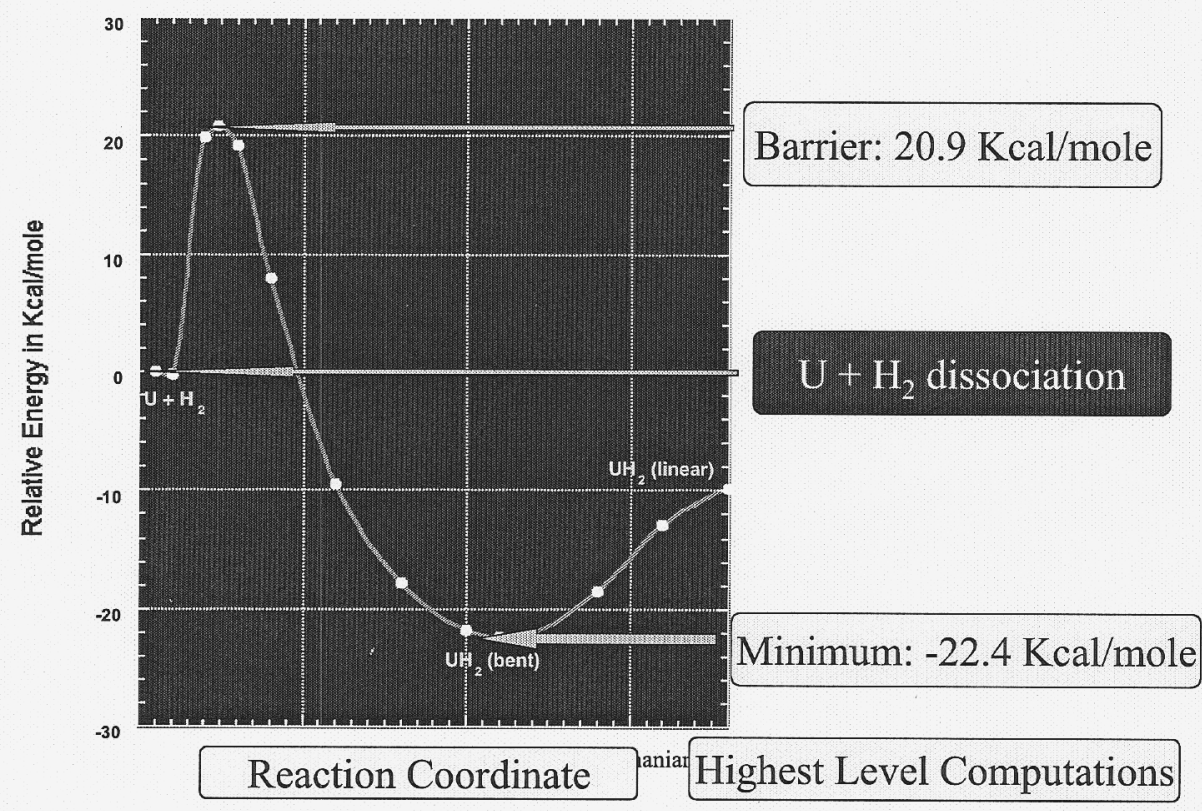

Figure 1 Potential Energy Surface for $\mathrm{U}-\mathrm{H}_{2}$ reaction

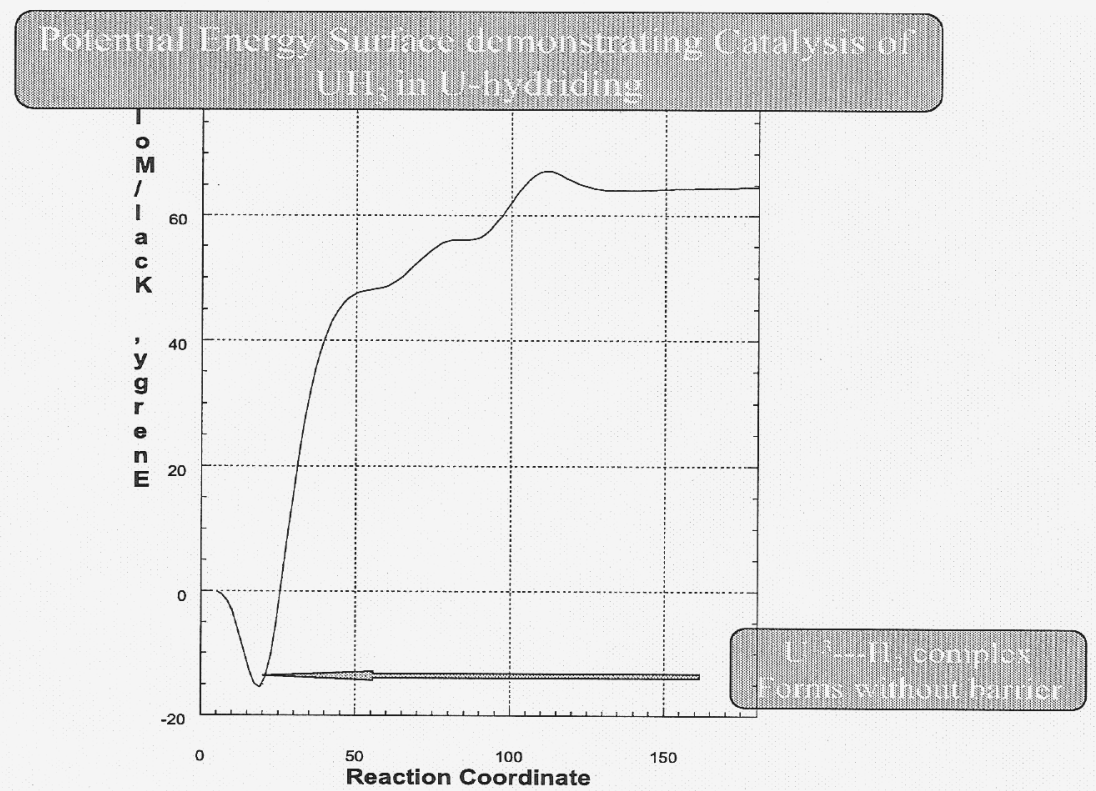

Figure 2 Potential Energy Surface for $\mathrm{UH}_{3}-\mathrm{H}_{2}$ interaction 